\title{
Representaciones sociales sobre la lectura en general y sobre la lectura literaria en docentes de escuelas primarias y públicas de San Miguel de Tucumán
}

ALEJANDRA MARÍA HUESPE Universidad Nacional de Tucumán - CONICET, Argentina / alehuespe@hotmail.com

\section{Resumen}

Este trabajo analiza las representaciones sociales sobre la lectura en general y sobre la lectura literaria que tienen los docentes del primer ciclo de primaria pertenecientes a tres escuelas públicas de la ciudad de San Miguel de Tucumán. A través de una serie de entrevistas semiestructuradas se indaga en biografías lectoras y trayectorias profesionales. Los resultados ponen en evidencia la coexistencia de representaciones asociadas a diferentes enfoques alfabetizadores que inciden de manera determinante en todo el espectro de sus configuraciones didácticas.

Palabras clave: representaciones / lectura / docentes / literatura / escuelas primarias / Tucumán

\section{Social representations about reading in general and about literary reading in teachers of primary and public schools in San Miguel de Tucumán \\ Abstract}

This article analyzes the social representations about reading and literary reading that the teachers of the first cycle of primary school belonging to three public schools of the city of San Miguel de Tucumán. Through a series of semi-structured interviews is investigated in reading biographies and professional trajectories. The results show the coexistence of representations associated with different literacy approaches that have a decisive impact on the entire spectrum of their didactic configurations.

Key words: representations / reading / teachers / primary schools / Tucumán 


\section{Introducción}

Este artículo indaga acerca de las representaciones sociales (Moscovici) sobre la lectura en general y sobre la lectura literaria en particular que tienen docentes pertenecientes a tres escuelas primarias y públicas de la ciudad de San Miguel de Tucumán. El interés por el tema se vincula con los primeros resultados que obtuvimos a partir de un estudio de campo de tipo etnográfico' que se llevó a cabo en las instituciones. El trabajo se realizó en el marco de una investigación doctoral ${ }^{2}$ que se encuentra en curso y que aborda la enseñanza de la literatura durante el proceso de alfabetización inicial, específicamente en el bloque la Unidad Pedagógica.

Los resultados iniciales demostraron que los textos literarios ingresan de manera eventual en las aulas. La frecuencia de trabajo con este tipo de textos está marcada por el diseño de la planificación docente y se expresa en forma de secuencias didácticas. La literatura tiene mayor presencia en las horas de lengua y, en menor medida, en el área de las ciencias sociales a través de materiales que se utilizan como disparadores para el trabajo de las efemérides escolares. A su vez se observó que, entre las entrevistas iniciales y las observaciones participantes realizadas, existían diferencias significativas en las concepciones de lectura que manejan los docentes. Se decidió entonces realizar una segunda instancia de entrevistas para obtener más información al respecto. Sobre el nuevo material recabado nos abocamos en este trabajo. El marco teórico utilizado para el análisis proviene principalmente de la psicología social, de la sociología, de la antropología de la lectura y de la de la didáctica de la literatura.

\section{Metodología}

La obtención de los datos en relación con las representaciones sociales sobre la lectura en general y sobre la lectura literaria se realizó a través de entrevistas formales semiestructuradas que fueron registradas en grabaciones de audio. Se tomó como informantes a los docentes pertenecientes a las tres escuelas incluidas en la investigación doctoral, con un total de doce personas consultadas. La muestra se construyó de manera intencionada siendo la primera condición que las instituciones sean primarias y públicas. La segunda condición se refiere a aspectos que tienen que ver la ubicación geográfica de la escuela con relación al centro de la ciudad ${ }^{3}$ y al nivel socioeconómico de la población estudiantil que asiste ${ }^{4}$ (Cuadro 1).

Cuadro 1: Muestra utilizada para la recolección de datos y variables tenidas en cuenta

\begin{tabular}{lllll}
\hline Escuela & Ubicación & Población estudiantil & Grado & Docente \\
\hline \multirow{2}{*}{ Escuela A } & $\begin{array}{l}\text { Urbano-periférica } \\
(6,8 \mathrm{~km} \text { del centro } \\
\text { de la ciudad })\end{array}$ & $\begin{array}{l}\text { Nivel socioeconómico } \\
\text { bajo }\end{array}$ & Primer Grado & Docente 1 \\
\cline { 4 - 5 } & & & Segundo Grado & Docente 2 \\
\hline \multirow{2}{*}{ Escuela B } & $\begin{array}{l}\text { Céntrica } \\
(2,5 \mathrm{~km} \text { del centro } \\
\text { de la ciudad })\end{array}$ & Nivel socioeconómico 3 \\
& bajo & Primer Grado & Docente 4 \\
\cline { 4 - 5 } & & Segundo Grado 5 & Docente 6 \\
\hline
\end{tabular}




\begin{tabular}{lllll}
\hline & & & Primer Grado & Docente 9 \\
Escuela C & $\begin{array}{l}\text { Céntrica } \\
(0,6 \mathrm{~km} \text { del centro } \\
\text { de la ciudad })\end{array}$ & Nivel socioeconómico & medio & Docente 10 \\
\cline { 3 - 4 } & & Segundo Grado & Docente 11 \\
& & & Docente 12 \\
\hline
\end{tabular}

\section{Cantidades totales}

\begin{tabular}{ll}
\hline Cantidad total de escuelas & 3 \\
\hline Cantidad total de grados & 6 \\
\hline Cantidad total de docentes & 12 \\
\hline
\end{tabular}

Por su parte, el diseño de las preguntas se orientó en dos líneas. La primera giró en torno a la experiencia escolar de los participantes. El objetivo fue identificar momentos de trascendencia en relación con su alfabetización inicial que pudieran dar indicios de la conformación de una identidad lectora. Para ello se indagó sobre los recuerdos que conservaban, sobre todo del primer grado; si tenían algún recuerdo del momento en que aprendieron a leer, escribir o algo en relación con ese proceso. Además, se preguntó sobre el acceso a algún tipo de biblioteca durante su infancia.

La segunda línea apuntó a reconocer las representaciones sociales que se construyeron a lo largo de su formación docente y en el ejercicio de su profesión. Para ello las preguntas los situaron en tiempo presente. En el marco de esas conversaciones se interrogó sobre qué consideraban que significa ser un lector y si para ellos era lo mismo ser lector que ser lector literario. La indagación sobre el concepto de lector literario se realizó posteriormente a la pregunta por el significado de lector en general. El momento adecuado para hacer esta pregunta se determinó a partir de la forma en que el informante construía la primera definición, con esto se buscó evitar condicionamientos en la respuesta. Luego se solicitó a los informantes que expliquen cómo se dan cuenta cuando sus alumnos ya saben leer. Por último, se les pidió que compartan sus ideas sobre qué características tiene que tener una biblioteca.

Entendemos a las representaciones sociales en el sentido en que lo propone Sergei Moscovici, es decir, como modalidades de conocimiento común que surgen en las experiencias de interacción e intercambio. Es en las prácticas sociales donde los individuos actúan con otros y ajustan su comportamiento a la vida social. Esto constituye «la realidad» para esos sujetos. Como se puede observar, partimos de la hipótesis de que las representaciones sociales sobre la lectura, construidas a lo largo de experiencias escolares y profesionales, inciden en el lugar que los docentes otorgan al texto literario en sus configuraciones didácticas ${ }^{5}$ (Litwin), es por ello que situamos este trabajo en la línea de estudios sobre las creencias del docente (Munita). Estudios anteriores demostraron que las experiencias, tanto pre-profesionales como profesionales, tienen un impacto significativo en la comprensión del objeto a enseñar (Tardiff). Acercarnos a ellas permitirá repensar posiciones y propiciar la reflexión acerca de las conceptualizaciones que orientan las prácticas en el aula. Esto resulta de interés, en especial en lo que respecta a los primeros años de la escuela primaria, por ser aquellos en los que se lleva adelante la enseñanza formal de la lectura y la escritura.

Es importante aclarar que no es el propósito de este trabajo realizar generalizaciones, sino dar a conocer los resultados obtenidos. Al estar localizada en un espacio geográfico específico, la 
información recabada contribuye a ampliar el espectro de datos sobre el tema. Asimismo, pueden ser confrontados o puestos en diálogo de manera que se configure un panorama más completo de la realidad de lo que sucede en las escuelas de la provincia.

\section{La alfabetización: un concepto sobre el que aún se debate}

El término alfabetización, que en su sentido más duro refiere a la enseñanza del alfabeto, se ha transformado a lo largo del tiempo. En la actualidad ha derivado en conceptualizaciones más complejas, como aquellas que tienen en cuenta niveles (emergente, inicial y avanzada) o que han migrado a nociones metafóricas como las de alfabetización digital, musical, científica, académica. Se trata entonces de un concepto alrededor del cual gravitan diversas significaciones. Berta Braslavsky (2005) señala que una primera dificultad al tratar de definir el concepto surge porque el mismo no aparece en la mayoría de los diccionarios, ni siquiera en los especializados en educación. Sugiere entonces la utilización de «la idea empíricamente aceptada (...) según la experiencia del siglo XX, que se expresaría en términos de una práctica elemental de lectura y escritura adquirida por las grandes mayorías» (36).

Para comprobar estas afirmaciones realizamos un rastreo en cuatro diccionarios y dos glosarios sobre temas educativos. Como era de esperarse, el terminó está ausente en cuatro de los seis textos consultados y en los dos restantes la palabra alfabetización se asocia únicamente a la alfabetización en personas adultas. ${ }^{6}$ Creemos que esto no se debe a un olvido o un descuido. Si seguimos un poco más adelante el término que sí aparece es el de analfabetismo: «Se le llama analfabeto a la persona que no sabe leer ni escribir»? Sobre este punto podemos realizar algunas consideraciones. La alfabetización entendida desde la ausencia (analfabetismo) naturaliza su presencia y no deja lugar a la discusión, pues implica la idea de que su definición no es necesaria. Creemos que la revisión de las conceptualizaciones sobre la alfabetización no puede ser dejada de lado puesto que aún existen 758 millones de personas en el mundo que no acceden a este derecho. ${ }^{8}$

A pesar de lo que ocurre en los diccionarios, las dificultades y las discusiones en torno a la definición no son nuevas. Otros autores señalaron la importancia de una precisión conceptual. Emilia Ferreiro habla sobre los inconvenientes que provoca el uso de términos que provienen de otras lenguas y que al ser traducidas no llegan a expresar la totalidad de significados que tienen en su origen. El término en inglés literacy en algunos casos se ha tomado como equivalente de alfabetización, mientras que en otro se ha convertido al español a través del vocablo literacidad. En una entrevista, Daniel Goldin pregunta a Ferreiro cómo traduciría, a lo que ella contesta:

\footnotetext{
En la colección de libros que estoy editando evito ese término: en muchos casos traduzco literacy como "cultura escrita», porque tiene sentido y sabemos de lo que estamos hablando; en otros contextos, literacy es alfabetización. Pero tampoco alfabetización es muy adecuado, porque resulta incómodo utilizar este término cuando tienes que hablar de «alfabetización en un sistema no alfabético». El término alfabetización está muy ligado al alfabeto. En este momento nadie se siente cómodo con los términos disponibles. (103)

En las prácticas de lectura y escritura subyace una concepción de fondo (Padilla). Comprender de qué se trata cada término, a qué línea de investigación o disciplina pertenece y sobre qué supuestos se sostienen, permite apreciar la complejidad de la noción de alfabetización y lo que implica su naturalización en las escuelas. Nuestro aporte consiste en dar cuenta de la problemática en el grupo de escuelas estudiado.
} 


\section{Tras las huellas de la práctica}

Ante la pregunta: ¿cuál es para vos el objetivo del primer ciclo?, la respuesta de los maestros consultados, aunque con matices, es siempre la misma: que los niños lean y escriban. A primera vista la afirmación parece acertada y es lo esperable si tenemos en cuenta que el nacimiento de la escuela se funda en este objetivo. Sin embargo, en el interior de las aulas es un camino que los llena de anhelos e incertidumbres. ${ }^{9}$ Se trata de una afirmación que repiten con vehemencia, pero con el temor de no saber si este objetivo será alcanzado por todos los alumnos.

Ahora bien ¿todos los docentes entienden lo mismo cuando hablan de lectura? ${ }^{10}$ En las entrevistan se observan representaciones sobre la lectura que provienen de diferentes enfoques alfabetizadores. Estas diferencias ponen de manifiesto tensiones que aún subsisten en los ámbitos académicos y que repercuten en las aulas en forma de «dificultades» a la hora de alfabetizar. Un ejemplo de lo que los docentes expresan como dificultad es el hecho de no poder trabajar ejercicios de aprestamiento con los niños, lo mismo sucede con la sistematización de los sonidos. Esto se debe a la existencia de un mandato de tipo ministerial que les prohíbe proponer actividades de este tipo en las aulas. En algunas instituciones esto se trasmite de manera soslayada a través de sugerencias que realiza el directivo, en otras es directamente un capacitador quien exige las modificaciones y genera el desconcierto del docente sobre lo que conoce y lleva adelante en su práctica.

Uno le tiene miedo a todo lo nuevo y nos ha parecido... no dábamos... no nos entraba. Ha venido una capacitadora... y bueno... yo algo de lo que entendía le decía a mi paralela». «Mirá, vamos a trabajar así y un día ha venido la capacitadora, nunca me olvido, y me dice... ¡Pero no! ¡Cómo va a hacer así! Y me ha tachoneado toda la carpeta. ¡No! ¡No es así, no es así!, dice, ¡Revea el material, revea! ¡No puede...! Y era como que yo me sentía una inútil, entonces no sé qué he entendido yo. (Docente 9)

Las tensiones remiten a disputas de larga data en relación con líneas y métodos de enseñanza que, lejos de estar superados, siguen vigentes y ponen en jaque a los docentes que se resisten a adherirse a las nuevas miradas. Se trata de la denominada querella entre los métodos de marcha sintética (alfabéticos, fónicos, silábicos) y los de marcha analítica (aquellos que parten de unidades significativas como la palabra, la oración, el texto) cuyos orígenes pueden rastrearse hasta el XVII y que sufrió una serie de resurgimientos, primero a mediados y luego a finales del siglo XX.

En Argentina la discusión tuvo más fuerza en la década del 6o. La implementación generalizada del método global sumado al alto índice de fracaso y repitencia (sobre todo en los primeros años de la escuela primaria) suscitó el rechazo de los docentes e instaló la disputa en todo el espectro social. En la década del 90 resurge en EE. UU. como espacio de controversias y aunque en nuestro país no tuvo el mismo impacto, es importante mencionar las discusiones ya que propiciaron la aparición de un nuevo enfoque denominado «equilibrado» que sí tuvo eco y que es el que se promovió luego desde las políticas educativas nacionales. La enseñanza equilibrada propone el consenso de las dos tendencias tradicionales y reconoce «la fuerza sinérgica de la suma de lo que cada una aporta a la alfabetización». No se trata de un consenso al que se llega a partir de acuerdos, sino como un «enfoque construido a partir del examen de un amplio espectro de la investigación» (Blair Larsen y William en Braslavsky 2005:101). 


\section{Las representaciones de los docentes}

El recuerdo constituye en sí mismo una forma de representación en la que se encuentra implicado un acto de voluntad. Paul Ricoeur siguiendo a Aristóteles establece la distinción entre el simple recuerdo (mnemé) y la rememoración (anamnesis). El recuerdo sobreviene motivado por una afección-pasión, mientras que la rememoración es producto del compromiso activo del sujeto por recordar. Este compromiso se traduce en términos de un «esfuerzo» de tipo intelectual. En las entrevistas se evidencia esta situación y se hace perceptible a través de la dificultad inicial por ubicar el momento del recuerdo. A todos los informantes les costó recordar, debieron entonces hacer el trabajo de la rememoración que quedó al descubierto en la medida en que expresaron necesitar un tiempo para que la memoria se active y puedan trasladarse a la edad en la que ahora están sus alumnos.

De sus experiencias escolares sobresalen imágenes del maestro de primer grado. En todos los casos es lo primero que mencionan. Se hace alusión a los aspectos físicos y a los gestos asociados con ellos. Estos pueden ser positivos o negativos y tienen que ver con la forma de calificar su desempeño como alumnos.

Recuerdo mi señorita, sus manos bien cálidas, era bien tierna. (Docente 2)

La maestra tenía un lunar grande cerca de la boca, una sonrisa grande. (Docente 5)

A través de la pareja de términos reflexividad-mundaneidad, Ricoeur postula la implicancia del cuerpo propio y el de los otros en el acto de rememoración. No es casual entonces que los primeros recuerdos sean sobre el cuerpo del maestro, su rostro, manos y sonrisa. A su vez estas representaciones se asocian a actitudes que los «marcaron».

Me acuerdo que era un cuento y que había que dibujar... parece un perrito y una pared con ladrillos y a mí no me salían los ladrillos y mi mamá me ayudó a dibujar esos ladrillos y la maestra me puso un gran cartel que decía: hacer las cosas sola... iiiterrible!!!(Docente 8)

El acto de calificar tiene connotaciones muy profundas en el psiquismo del alumno. Una mala nota o un reto así como también las actitudes de aprobación son acciones que se «inscriben» en el interior del sujeto y dejan «huellas» que se activan y que están ligadas al cuerpo del otro, al propio y a las emociones que suscitan. Además de esto, en los recuerdos también aparecen objetos. El objeto por antonomasia es el cuaderno, aunque existen referencias a manuales escolares utilizados en su infancia, o algún libro de cuentos.

Trabajábamos igual que ahora, con un cuadernito así, alto. (Docente 7)

Me acuerdo del librito. Eran tan lindos los dibujos de la madre. Era tan bonita. (Docente 2)

Otra recurrencia para destacar es que ninguno de los docentes tiene recuerdos vinculados con el momento en que aprendió a leer. Se trata de un punto importante porque consideramos que impacta en las representaciones a través de una naturalización de la lectura.

No me he dado cuenta cuando aprendí a leer. No me he dado cuenta, de decir: ya estoy leyendo. (Docente 11) 
Yo no me acuerdo de nada, han pasado tantos años. 50 años ya. (Docente 12)

No me acuerdo. Creo que nací leyendo. (Docente 7)

Los docentes se miran a sí mismos como si ser lector fuera algo natural. La práctica se incorporó de tal manera en la vida cotidiana que muchas veces no reparan en el enorme esfuerzo que conlleva este proceso.

Con respecto a las representaciones sobre la lectura en relación con una mirada actual y como profesionales, los datos muestran que, para los docentes informantes, un lector es el que puede leer el mundo e interpretarlo, no sólo es el que lee palabras escritas, también es el que puede leer imágenes.

Lector somos todos. No necesariamente el texto escrito. Hacemos lectura de imágenes, hacemos lectura del mundo. (Docente 12)

¿Qué es un lector? Para mí el apasionado. El que todo le interesa, el que quiere aprender más. (Docente 2) Si no hay palabras, no hay letras, te puede contar una imagen. (Docente 1)

No obstante, al ser interrogados sobre cómo se dan cuenta de que sus alumnos ya son lectores, sobresale la idea de que aprendieron a leer cuando pueden sonorizar lo que está escrito en el pizarrón.

Por ejemplo ahora, dos nenitas la semana pasada se acercan y me dicen «Mirá Señorita...» querían adelantarse y que yo les explique las consignas. Y tuve una sensación de alegría, la alegría de las dos de darnos cuenta de que ella estaba leyendo, y empieza de a poquito, las dos nenas... la iba siguiendo la otra con el dedito y asociando y le iban saliendo las palabritas. (Docente 1)

Este ejemplo es uno de los tantos que dan cuenta de que, a la hora de dilucidar las conceptualizaciones más profundas, los docentes asocian inevitablemente la lectura a la decodificación fonológica. Sus alumnos pueden considerarse «lectores» en el momento en que dan cuenta de haber desarrollado esta conciencia" y pueden utilizarla de manera autónoma. Señalamos especialmente este supuesto ya que conlleva la idea de que los niños en proceso de adquisición de la alfabetización inicial no pueden ser considerados «lectores completos». Detrás de esta representación subyace una idea de lectura que condiciona el espectro de posibilidades de acceso a los textos. De esta forma la literatura se ve circunscripta a la variable de la funcionalidad o de la no funcionalidad que transforman al texto literario en «herramienta» para enseñar eso que consideran que significa realmente «leer». Esto explica de alguna manera el hecho de que los textos con los que comienzan los niños su aprendizaje de la lectura y la escritura son aquellos que exponen de manera más transparente las cinco vocales.

Hacer visible esta situación permite repensar cristalizaciones que dan por resultado obstáculos epistemológicos ${ }^{12}$ (Bachellard, Camilloni, Gerbaudo) que no permiten al docente realizar elecciones cada vez más conscientes y fundamentadas. Además, lo expuesto hasta aquí contribuye a comprender una de las causas de la supervivencia de actividades de aprestamiento y de metodologías asociadas a unidades no significativas de la lengua. Decimos esto porque, entre otras cosas y pese al esfuerzo infructuoso de las políticas educativas por acercar la práctica docente al enfoque equilibrado, el trabajo de campo revela que las actividades de aprestamiento, copia y el ejercicio mismo de decodificación siguen vigentes a través de diversas estrategias de simulación. 
Los docentes matizan estas actividades incluyéndolas dentro de otras, trabajándolas en cuadernillos aparte, o simplemente borrándolas del soporte escrito (se las trabaja en el pizarrón pero no se las copia en el cuaderno). El origen de esta situación se ubica en las experiencias iniciales con la alfabetización que tuvieron los docentes cuando eran niños y que contribuyen a sostener una concepción de lectura ligada a la decodificación fonológica. Se trata de un habitus ${ }^{13}$ (Bourdieu y Passeron) del que no tienen conciencia plena pero que influye en sus decisiones. El resultado es una deriva metodológica que los lleva a la combinación desarticulada de enfoques tradicionales con nuevas perspectivas.

En relación con el trabajo vinculado a la biblioteca la operación es similar. Al ser consultados, la mayoría de los docentes caracterizan a ese espacio con adjetivos como completa, rotulada, clasificada, abierta, iluminada. Es importante señalar que las tres instituciones relevadas poseen biblioteca, pero se pudo comprobar que su utilización es muy escasa. Al avanzar en las entrevistas y al ampliar la cantidad de informantes, una de las respuestas devela una clave fundamental. Al ser interrogada sobre qué características tiene que tener una biblioteca, una docente de segundo ciclo responde:

¿Qué? ¿Tu biblioteca o la biblioteca de la escuela?... Pienso que la nuestra se va haciendo según tus gustos (...) La de la escuela tiene que ser completa, de todo, sería lo ideal, y todo rotulado. Vos te acercás y tenés que saber dónde están [los libros].

La pregunta es una generalidad, es ella la que, a través de su interpretación, marca la diferencia entre biblioteca personal y biblioteca escolar. Se le pregunta entonces qué libros no podrían faltar y agrega:

¿Qué libros no podrían faltar? Y obvio... no, pero a mí me van a gustar los libros que a mí me gusten, no de los niños, no puede haber de esos. No puedo decir... porque tiene que ser lo que a mí me guste. Estoy pensando para mí, cosa equivocada porque uno tiene que pensar para los niños, para ellos. Los que sirvan para los niños.

Pierre Bourdieu sostiene que para explicar las acciones sociales - hasta donde ello es posible- no es suficiente valerse de la sola descripción de las condiciones objetivas. Es importante también rescatar al agente social que produce las prácticas y a su proceso de producción. Esta actitud metodológica lleva necesariamente a sustituir la relación ingenua entre el individuo y la sociedad por la relación construida entre dos modos de existencia de lo social: las estructuras sociales externas, lo social hecho cosas, plasmado en condiciones objetivas, y las estructuras sociales internalizadas. Las estructuras sociales externas se refieren a campos de posiciones sociales históricamente constituidos mientras que las internas remiten habitus, sistemas de disposiciones incorporados por los agentes a lo largo de su trayectoria social.

Una manera posible de introducir cambios en los habitus es a través de un proceso de autosocioanálisis. Mediante un análisis reflexivo de uno de los condicionantes objetivos de las propias prácticas, el agente social puede permitirse trabajar para modificar sus percepciones y representaciones de los condicionantes externos de sus prácticas, y de ellas mismas, y por lo tanto elaborar estrategias diferentes de acción (Gutiérrez). 
Como se observa en el ejemplo, la pregunta realizada a la docente dispara la activación de un autoanálisis que confronta y le permite el reconocimiento de una posición y de una disposición (Bourdieu) con relación al capital cultural con la que ella venía operando en el juego del campo social. La imposibilidad de pensarse a sí misma como un lector que forma parte de la comunidad escolar abre una brecha entre su práctica y la de los niños. Al posicionarse por fuera opera como un agente externo que sólo «ejecuta» una práctica de la que está excluida. Esto permite comprender, de alguna manera, la tan escasa utilización de las bibliotecas escolares y a su vez, la eventualidad de la literatura en sus configuraciones didácticas. Al no tener acceso a una amplia gama de materiales literarios, el corpus de textos en sus planificaciones se limita a aquello que conoce o a aquellos textos que son sugeridos por los acompañantes territoriales de los equipos ministeriales.

Por último, es importante mencionar que a los entrevistados les resultó muy difícil pensar la diferencia entre lector y lector literario. Como herencia de las políticas educativas de los años 90 y anclados en una perspectiva lingüística y comunicativa, en muchos docentes subyace la idea de que el texto literario es un tipo de clase textual más, como pueden ser la noticia o la receta. Sólo en un caso, una docente arriesga una respuesta más específica «El lector literario es el que puede elegir» (Docente 4). La respuesta tiene que ver con lo que observamos en las prácticas y que podemos resumir en la idea de un docente que no se siente habilitado para realizar elecciones.

Concluimos entonces en que resulta indispensable repensar el lugar del docente como lector en general, pero sobre todo como lector literario. Investigar a fondo esos recorridos personales, esas textotecas, tal como los define Laura Devetach. Los datos anticipan caminos angostos, unidireccionales, a veces interrumpidos o atascados temporariamente en sus biografías lectoras. Resulta imposible poder acompañar a los niños sin haber tenido experiencias significativas con la lectura. Esto permitirá reposicionar también la lectura literaria y abrir el corpus de textos hacia aquellos que sean factibles de ser abordados por una lectura de tipo estética ${ }^{14} \mathrm{y}$ de esta forma evitar su innecesaria instrumentalización.

\section{Notas}

1 El trabajo de campo se realizó entre marzo de 2015 y junio de 2016.

2 La misma cuenta con el financiamiento del Consejo Nacional de Investigaciones Científicas y Técnicas (CONICET) y se realiza bajo la dirección de la Dra. María Jesús Benites (UNT-CONICET).

3 Para determinar el centro se tomó como referencia lo que se considera el kilómetro o de la provincia representado por la ubicación de su plaza principal, la Plaza Independencia.

4 El nivel socioeconómico de la población estudiantil es un indicador sintético que considera la combinación de un conjunto de variables. Para el nivel primer primario las variables estipuladas por el Ministerio de Educación son: el nivel educativo de los padres, el nivel de hacinamiento en el hogar y el acceso a la tecnología. La información se obtiene de los registros de alumnos.

5 Edith Litwin define la configuración didáctica como la manera particular que despliega el docente para favorecer los procesos de construcción del conocimiento. Esto implica una construcción elaborada en la que se pueden reconocer los modos como el docente aborda múltiples temas de su campo disciplinar y que se expresan en el tratamiento de los contenidos, su particular recorte, los supuestos que maneja respecto del aprendizaje, la utilización de prácticas metacognitivas, los vínculos que establece en las clases con las prácticas profesionales involucradas en el campo de la disciplina de que se trata, el estilo de la negociación de significados que genera, las relaciones entre la práctica y la teoría que incluyen lo metódico y la particular relación entre el saber y el ignorar (Litwin en Gerbaudo:128). 
6 Los diccionarios y glosarios consultados se consignan en la bibliografía.

7 La cursiva me pertenece.

8 Datos tomados del último informe de la UNESCO.

9 La regularidad en las respuestas se determinó a partir de las primeras entrevistas, mientras que las incertidumbres fueron detectadas a través de comentarios que fueron referidos durante las observaciones participantes.

10 Nos concentramos en las representaciones sobre la lectura porque reconocemos, a la luz de las nuevas investigaciones, a la lectura y la escritura como dos procesos diferenciados.

11 Se denomina conciencia fonológica (o reflexión metafonológica) al conocimiento declarativo explícito del niño acerca de las posibilidades de manipulación deliberada de los rasgos estructurales del habla. La recodificación fonológica, por su parte, es el conocimiento procedimental que permite el ensamblaje o síntesis de los fonemas para generar la pronunciación (sonorización) de una cadena de letras basado en el dominio de la correspondencia entre fonema y grafema (Signorini en Marder).

12 Sigo a Analía Gerbaudo cuando utiliza de manera análoga a Alicia Camilloni el concepto de obstáculo epistemológico de Gastón Bachelard. Se denomina obstáculo epistemológico a aquello que se sabe y que bajo la forma de saber-cristalizado, genera inercias que dificultan la reflexión sobre el objeto.
Gerbaudo plantea que es necesario detectar cuáles son los que afectan al campo de la enseñanza de la literatura para tratar de descolocarlos teniendo presente que jugará en contra de este procedimiento la tendencia a confirmar lo que se cree más que la alerta respecto de lo que contradice dichas creencias. Cuando en el marco de una comunidad no aparecen interrogantes sino sólo respuestas, o cuando una se fija (a modo de ritual o receta), «el obstáculo epistemológico se incrusta sobre el conocimiento que ya no se cuestiona» (Camilloni en Gerbaudo).

13 Bourdieu define al habitus como el «grupo de esquemas que permiten crear una infinidad de prácticas adaptadas a situaciones siempre renovadas, sin constituir jamás principios explícitos (...) o un sistema de disposiciones duraderas y adaptables que, al integrar todas las experiencias pasadas, funcionan a cada momento como una matriz de percepciones, de apreciaciones y de acciones y hace posible el cumplimiento de tareas infinitamente diferenciadas, gracias a las transferencias analógicas de esquemas, que permiten resolver problemas que tienen la misma forma (Bourdieu en Perrenaud:29-30).

14 Nos basamos en la clasificación de Louis Rosenblatt quien distingue la lectura «estética» de la lectura de tipo «eferente». La lectura estética tiene que ver con una experiencia de tipo emocional mientras que la eferente es aquella que tiene como propósito sólo la extracción de información.

\section{Referencias bibliográficas}

Bachelard, G. (1988). La formación del espíritu científico. Contribución a un Psicoanálisis del Conocimiento Objetivo. México: Siglo XXI.

Braslavsky, B. P. de (2004). ¿Primeras letras o primeras lecturas?: Una introducción a la alfabetización temprana. Buenos Aires: Fondo de Cultura Económica.

(2005). Enseñar a entender lo que se lee. La alfabetización en la familia y en la escuela. Buenos Aires: Fondo de Cultura Económica.

Camilloni, A. (1997) Los obstáculos epistemológicos en la enseñanza. España: Gedisa.

Bourdieu, P. y Passeron, J. C. (1977). La Reproducción. Barcelona: Laia.

Caspari, D. (2003). Fremdsprachenlehrer: Studien zu ihrem beruflichen Selbstverständnis. Tübingen: Gunter Narr Verlag. Devetach, L. (2008). La construcción del camino lector. Córdoba: Comunicarte.

Ferreiro, E. (1991). La construcción de la escritura en el niño. Lectura y Vida. Revista Latinoamericana de lectura, 2(12), 5-14.

(2014). Cultura escrita y educación. México: Fondo de Cultura Económica.

Granado, C. y Puig, M. (2014). La identidad lectora de los maestros en formación como componente de su identidad docente. Un estudio de sus autobiografías como lectores. Ocnos, (13), 43-63. 
Gutiérrez, A. B. (2005). Las prácticas sociales: una introducción a Pierre Bourdieu. Córdoba: Ferreyra Editor.

Gerbaudo, A. (2006). Ni dioses ni bichos, Profesores de literatura, curriculum y mercado. Santa Fe: Universidad Nacional del Litoral.

Litwin, E. (1997). Las configuraciones didácticas Una nueva agenda para la enseñanza superior. Buenos Aires: Paidós.

Marder, S. E. (2008). Impacto de un programa de alfabetización temprana en niños de sectores urbano marginales. Tesis presentada para la obtención del grado de Doctora en Psicología. Universidad Nacional de Mar del Plata. www.memoria.fahce.unlp.edu.ar/tesis/te.734/te.734.pdf

Moscovici, S. (1979). El psicoanálisis, su imagen y su público. Buenos Aires: Huemul.

Munita, F. (2014). El mediador escolar de la lectura literaria. Un estudio del espacio de encuentro entre prácticas didácticas, sistemas de creencias y trayectorias personales de lectura. Barcelona: Universitat Autònoma de Barcelona.

Padilla, C. (2004). Modelos procesuales de comprensión y producción escrita: fundamentos de una didáctica de las lenguas. La didáctica de las lenguas. Reflexiones y propuestas. Maestría en Didáctica de las Lenguas. Tucumán: Universidad Nacional de Tucumán, 175-193.

Perrenaud, P. (2002). Construir competencias desde la escuela. Santiago de Chile: Océano.

Pineau, P. (2004). La lectura escolary la construcción de la culturas políticas. Una mirada histórica para el caso argentino. Proyecto UBACyT FO52 (2004-2007). Instituto de Investigaciones en Ciencias de la Educación, Facultad de Filosofía y Letras. Universidad de Buenos Aires.

Ramos Méndez, C. (2007). El pensamiento de los aprendientes en torno a cómo se aprende una lengua: Dimensiones individuales y culturales (ASELE, Colección Monografías, $\mathrm{N}^{\circ} 10$ ). Ministerio de Educación y Ciencia.

Ricoeur, P. (2004). La memoria, la historia, el olvido. Buenos Aires: Fondo de Cultura Económica.

Rosenblatt, L. M. (2003). La literatura como exploración. Madrid: Fondo de Cultura Económica.

Tardiff, M. (2004). Los saberes del docente y su desarrollo profesional. Madrid: Narcea.

\section{Diccionarios, Enciclopedias y Glosarios}

Diccionario Akal de Pedagogía (2001). Autor: Horst Schaub. Editorial Akal.

Diccionario Enciclopédico de Ciencias de la Educación (2005). Autores: Oscar Picardo Joao, Juan Carlos Escobar Baños, Rolando Valmore Pacheco Cardoza. El Salvador: Centro de Investigación Educativa.

Diccionario de pedagogía, didáctica y metodología (2012). Autor: Alexander Ortiz Ocaña. http://www. autoreseditores.com/book_preview/pdf/oooooo716.pdf?1469473878

Diccionario de términos educativos (2007). Editorial Máster Distancia.

Glosario pedagógico (2007). Autores: Yoselin Martínez Renedo, Fernando Pablo Hernández e Irán Danae

Quevedo Fabela. Facultad de Estudios Superiores «Acatlán». Universidad Nacional Autónoma de México. Nuevo glosario de términos para Docentes, Directivos y Asesores Académicos de Educación Básica (2012). 